\title{
An experimental study on performance and emission characteristics of a hydrogen fuelled spark ignition engine
}

\author{
Erol Kahraman ${ }^{\mathrm{a}}$, S. Cihangir Ozcanlı ${ }^{\mathrm{b}}$, Baris Ozerdem ${ }^{\mathrm{b}, *}$ \\ ${ }^{a}$ Program of Energy Engineering, Izmir Institute of Technology, Urla, Izmir 35430, Turkey \\ ${ }^{\mathrm{b}}$ Department of Mechanical Engineering, Izmir Institute of Technology, Urla, Izmir 35430, Turkey \\ Received 2 August 2006; accepted 2 August 2006 \\ Available online 2 October 2006
}

\begin{abstract}
In the present paper, the performance and emission characteristics of a conventional four cylinder spark ignition (SI) engine operated on hydrogen and gasoline are investigated experimentally. The compressed hydrogen at $20 \mathrm{MPa}$ has been introduced to the engine adopted to operate on gaseous hydrogen by external mixing. Two regulators have been used to drop the pressure first to $300 \mathrm{kPa}$, then to atmospheric pressure. The variations of torque, power, brake thermal efficiency, brake mean effective pressure, exhaust gas temperature, and emissions of $\mathrm{NO}_{x}, \mathrm{CO}, \mathrm{CO}_{2}, \mathrm{HC}$, and $\mathrm{O}_{2}$ versus engine speed are compared for a carbureted SI engine operating on gasoline and hydrogen. Energy analysis also has studied for comparison purpose. The test results have been demonstrated that power loss occurs at low speed hydrogen operation whereas high speed characteristics compete well with gasoline operation. Fast burning characteristics of hydrogen have permitted high speed engine operation. Less heat loss has occurred for hydrogen than gasoline. $\mathrm{NO}_{x}$ emission of hydrogen fuelled engine is about 10 times lower than gasoline fuelled engine. Finally, both first and second law efficiencies have improved with hydrogen fuelled engine compared to gasoline engine. It has been proved that hydrogen is a very good candidate as an engine fuel. The obtained data are also very useful for operational changes needed to optimize the hydrogen fueled SI engine design.
\end{abstract}

(C) 2006 International Association for Hydrogen Energy. Published by Elsevier Ltd. All rights reserved.

Keywords: Hydrogen; SI engine; Emission characteristics; Performance characteristics

\section{Introduction}

Fossil fuels such as petroleum, natural gas and coal meet most of the world's energy demand, at present time. But combustion products of these fossil fuels, such as carbon monoxide $(\mathrm{CO})$, carbon dioxide $\left(\mathrm{CO}_{2}\right)$, oxides of sulfur $\left(\mathrm{SO}_{x}\right)$, oxides of nitrogen $\left(\mathrm{NO}_{x}\right)$, hydrocarbon $(\mathrm{HC})$, toxic metals, and ashes have been causing many environmental problems and posing great danger for the world. It is very well known that the solution to these problems is to replace the existing fossil fuel systems with the clean renewable energy ones, even though this could impose some design modifications [1,2]. Therefore, alternative fuel research becomes the main purpose nowadays.

Hydrogen is a renewable energy based, practically carbonfree, and light gaseous alternative fuel. The use of hydrogen as

\footnotetext{
* Corresponding author. Tel.: +90 2327507801 ; fax: +90 2327507890 .

E-mail address: barisozerdem@iyte.edu.tr (B. Ozerdem).
}

an alternative engine fuel fulfils certain basic criteria such as availability, high specific energy content, minimum pollution, easy and safety storage along with transportation. Hydrogen has proved its suitability over many fuels in these criteria. Hydrogen does not cause combustion problems such as vapor lock, cold wall quenching, inadequate vaporization or poor mixing, and does not produce toxic products. Its heating value is high on mass basis whereas low on volume basis. Due to together with its other thermo-physical properties, hydrogen has unique and desirable heat transfer characteristics. It can be noticed that hydrogen does not occur in its free form naturally. Hydrogen can be produced by using fossil fuels such as oil, coal and natural gas or renewable energy resource as water. Hydrogen in high purity can be produced through the electrolysis of water. The required electrical power can be supplied by renewable energy resources such as solar, wind, wave, tide or hydraulics.

Internal combustion engines are classified as spark ignition (SI) and compression ignition (CI) engines, depending on the 


\begin{tabular}{|c|c|c|c|}
\hline \multicolumn{4}{|c|}{ Nomenclature } \\
\hline$b$ & distance from rotor center, $\mathrm{m}$ & $P_{0}$ & surroundings pressure, $\mathrm{kPa}$ \\
\hline BMEP & brake mean effective pressure, $\mathrm{kPa}$ & $\dot{Q}_{\mathrm{k}}$ & heat transfer rate through the boundary, $\mathrm{kW}$ \\
\hline & compression ignition & $Q_{\mathrm{LHV}}$ & lower heating value of fuel, $\mathrm{kj} / \mathrm{kg}$ \\
\hline $\mathrm{CNG}$ & compressed natural gas & SI & spark ignition \\
\hline $\mathrm{CO}$ & carbon monoxide & $\mathrm{SO}_{x}$ & oxides of sulfur \\
\hline $\mathrm{CO}_{2}$ & carbon dioxide & $T$ & brake torque, $\mathrm{Nm}$ \\
\hline & differential operator & $T_{\mathrm{k}}$ & system boundary temperature, $\mathrm{K}$ \\
\hline $\begin{array}{l}\text { d } t \text { t } \\
\text { DLR }\end{array}$ & German Aerospace Research Establishment & $T_{0}$ & surroundings temperature, $\mathrm{K}$ \\
\hline$F$ & load, $N$ & TDC & top dead center \\
\hline $\mathrm{HC}$ & hydrocarbon & $V_{\mathrm{d}}$ & total volume of the engine cylinders, $\mathrm{dm}^{3}$ \\
\hline I & irreversibility, kj & $V_{\text {system }}$ & system volume, $\mathrm{m}^{3}$ \\
\hline$\dot{I}$ & rate of irreversibility, $\mathrm{kj} / \mathrm{s}$ & $\dot{W}$ & rate of work, $\mathrm{kj} / \mathrm{s}$ \\
\hline$\dot{m}_{\mathrm{f}}$ & mass of supplied fuel, $\mathrm{kg} / \mathrm{s}$ & $\dot{X}$ & rate of net exergy transfer, $\mathrm{kj} / \mathrm{s}$ \\
\hline$\dot{m}_{\text {in }}$ & inlet mass flow rate, $\mathrm{kg} / \mathrm{s}$ & $\dot{X}_{\text {destroyed }}$ & rate of exergy destruction, $\mathrm{kj} / \mathrm{s}$ \\
\hline$\dot{m}_{\text {out }}$ & outlet mass flow rate, $\mathrm{kg} / \mathrm{s}$ & $\varepsilon$ & second-law efficiency \\
\hline MEP & mean effective pressure, $\mathrm{kPa}$ & $\psi_{\text {in }}$ & specific inlet flow exergy, $\mathrm{kj} / \mathrm{kg}$ \\
\hline$n_{\mathrm{r}}$ & $\begin{array}{l}\text { the number of crank revolutions for one com- } \\
\text { plete cycle }\end{array}$ & $\begin{array}{l}\psi \text { out } \\
\pi\end{array}$ & $\begin{array}{l}\text { specific outlet flow exergy, } \mathrm{kj} / \mathrm{kg} \\
\text { pi number }\end{array}$ \\
\hline $\mathrm{NO}_{x}$ & oxides of nitrogen & $\eta_{\mathrm{BT}}$ & brake thermal efficiency \\
\hline $\mathrm{O}_{2}$ & oxygen & $\omega$ & angular speed, rps \\
\hline$P_{\mathrm{b}}$ & brake power, $\mathrm{kW}$ & & \\
\hline
\end{tabular}

combustion process initiated in the cylinder. A spark plug initiates the combustion of the fuel-air mixture in SI engines. In $\mathrm{CI}$ engines, fuel-air mixture is self-ignited by compression. It must be mentioned that hydrogen's auto-ignition temperature is high (about $576^{\circ} \mathrm{C}$ ), and it is impossible to bring hydrogen to its auto-ignition temperature by compression only. So, supportive ignition triggering devices should be used in the combustion chamber.

Many researchers have been directed their studies towards the effect of using hydrogen in internal combustion engines [3-11]. Das et al. [3], evaluated the potential of using hydrogen for small horsepower SI engines and compared hydrogen fuelling with compressed natural gas $(\mathrm{CNG})$. Another study dealt on certain drawbacks of hydrogen fuelled SI engines, such as high $\mathrm{NO}_{x}$ emission and small power output [4]. Das [5] determined the performance, emission and combustion characteristics of hydrogen fuelled SI and CI engines. Karim [6] reviewed the design features and the current operational limitations associated with the hydrogen fuelled SI engine. $\mathrm{Li}$ and Karim [7] investigated the onset of knock in hydrogen fuelled SI engine applications. Since the compression ratio as high as 29 was not enough to achieve ignition of hydrogen for a hydrogen fuelling CI engine, a comparative assessment showed that $\mathrm{CI}$ engines can be converted to operate on hydrogen-diesel dual mode without sacrificing the performance parameters [8]. Effect of compression ratio, equivalence ratio and engine speed on the performance and emission characteristics of a SI engine using hydrogen as a fuel was investigated by Al-Baghdadi [9]. The effect of methane and ethyl alcohol addition on the performance and emission characteristics of SI engines operating on fuel mixtures containing hydrogen was also investigated by some researchers $[10,11]$. The car making companies have been trying to employ the hydrogen as a fuel for some years, as well. The Mazda company has delivered first hydrogen dual fuel vehicle named RX-8 Hydrogen RE. It is equipped with rotary engine and features a dual fuel system with electronically controlled injector system that allows the driver to select either hydrogen or gasoline [12] . The BMW company is presented a prototype car named H2R. It showed that hydrogen can replace conventional fuel without reducing the performance of a modern automobile [13]. The German Aerospace Research Establishment (DLR) used cryogenic hydrogen with hybrid mixture formation on a BMW 745i vehicle in a joint effort with the BMW company. Satisfactory achievements were made by hybrid mixture formation in means of power and torque characteristics under steady and intermittent operating conditions [14].

But the data obtained from these researches are not consistent and have a tendency to describe specific engine operations. Obviously, there is a need to focus both on the positive features as well as the limitations and drawbacks that need to be solved for hydrogen to become an accepted fuel for internal engine applications. There is also a need to indicate practical steps for the usage of hydrogen to develop design measures and to improve its performance as an engine fuel. Moreover, the greater emphasis on the emissions and efficiency considerations, especially in exergetic manner, makes much of the previous works fragmentary. Therefore, there is an increasing interest in the studies on performance and pollutant emissions of hydrogen fueled conventional internal combustion engines.

This experimental study examines the performance and emission characteristics of a hydrogen fueled conventional 
4-cylinder SI engine. The variations of brake torque, brake power, brake thermal efficiency, brake mean effective pressure, exhaust gas temperature, and emissions of $\mathrm{NO}_{x}, \mathrm{CO}, \mathrm{CO}_{2}, \mathrm{HC}$, and $\mathrm{O}_{2}$ versus engine speed are presented and compared for the gasoline and hydrogen operations. Besides these points, both energy and exergy efficiencies are studied for comparison purposes, as well. In addition, slight engine design modifications made for hydrogen feeding and operation without changing the basic characteristics of the original engine are discussed.

\section{Experimental setup and procedure}

The tests were performed at the Engines Laboratory of Dokuz Eylul University at Izmir. The laboratory consists of test benches involving an eddy current-type dynamometer, exhaust emission analyzer, fuel metering device and auxiliary equipment. Fig. 1 illustrates the basic setup of the test bench.

The engine was Fiat licensed one produced by the Tofas company. Besides the engine itself, flywheel, starting motor, alternator, fuel pump, fuel tank, dashboard and exhaust assemblies were mounted to the proper places. The engine specifications are shown in Table 1.

The engine was coupled with its original shaft to the dynamometer. The control panel of the dynamometer was placed at a safe but easily accessible distance from the setup. The ambient pressure and temperature, engine speed and torque values were easily read from the large size gauges. The compressed hydrogen at $20 \mathrm{MPa}$ was supplied by $50-1$ steel gas tanks. The first stage regulator installed on the steel gas tank was used to drop the gas pressure to $300 \mathrm{kPa}$. The second stage regulator installed above the radiator of engine drops the supplied hydrogen to atmospheric pressure for the mixing apparatus placed on the inlet manifold. A conversion kit was used for hydrogen feeding. The exhaust gas composition of the engine was
Table 1

Engine specifications [18]

\begin{tabular}{ll}
\hline Type & Fiat licensed Tofas 124 \\
\hline Cycle & Four-stroke \\
Cylinder number & 4 \\
Cylinder bore & $73 \mathrm{~mm}$ \\
Stroke & $71.5 \mathrm{~mm}$ \\
Swept volume & $1197 \mathrm{cc}$ \\
Compression ratio & $8.8: 1$ \\
Power & $60 \mathrm{HP}$ (DIN) at $5600 \mathrm{rpm}$ \\
Torque & $89 \mathrm{Nm}$ at $3400 \mathrm{rpm}$ \\
Ignition & Distributor type, $10^{\circ}$ static advance \\
Fuel feeding & Solex 2 barrel carburetor \\
Exhaust & Standart muffler with silencer \\
\hline
\end{tabular}

analyzed by the gas analyzer, Sun MGA 1200 , for $\mathrm{CO}, \mathrm{CO}_{2}$, $\mathrm{O}_{2}$, and $\mathrm{HC}$. The engine speed, gas temperature and air-fuel ratio were also measured by this equipment. For $\mathrm{NO}_{x}$ readings, an emission monitoring device, MRU Vario D52, was used.

Table 2 shows properties of the used fuels: hydrogen and gasoline. It can be seen from Table 2 that, some of the unique features of hydrogen are low density, low boiling point, and high calorific values.

The experiments were carried out on a four-cylinder, fourstroke, SI engine with carburetor as the fuel induction mechanism. Fig. 2 gives an overview of the test engine.

During the tests, addition of spray nozzles for water was essential to provide backfire-free operation. The spray nozzles were placed $40 \mathrm{~mm}$ away from the inlet valves. Preignition can cause backfire when ignited air-fuel mixture explodes backward into the inlet valve system. The ignition timing was set to $10^{\circ}$ before top dead center (TDC) and then fixed. It should be noted that, the higher engine speed requires the more amount of water.

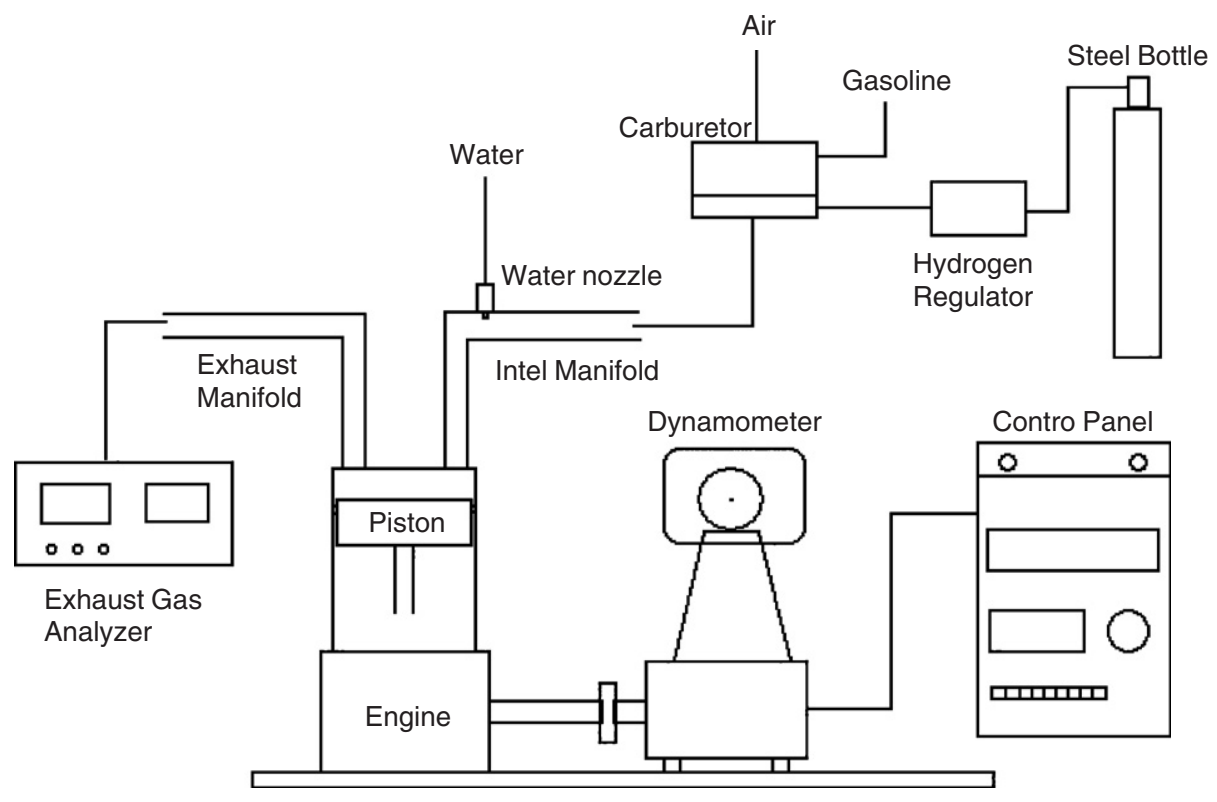

Fig. 1. Block diagram of test setup. 
Table 2

Properties of hydrogen and gasoline [18]

\begin{tabular}{lll}
\hline Property & Hydrogen & Gasoline \\
\hline $\begin{array}{l}\text { Density at } 1 \mathrm{~atm}, 300 \mathrm{~K}\left(\mathrm{~kg} / \mathrm{m}^{3}\right) \\
\text { Stoichiometric composition in air }\end{array}$ & 0.082 & 5.11 \\
$(\%$ by volume) & 29.53 & 1.65 \\
LHV $(\mathrm{MJ} / \mathrm{kg})$ & 119.7 & 44.79 \\
$\begin{array}{l}\text { Combustion energy } \\
\text { (MJ/kg stoichiometric mixture) }\end{array}$ & 3.37 & 2.79 \\
Autoignition temperature $(\mathrm{K})$ & 858 & $500-750$ \\
\hline
\end{tabular}

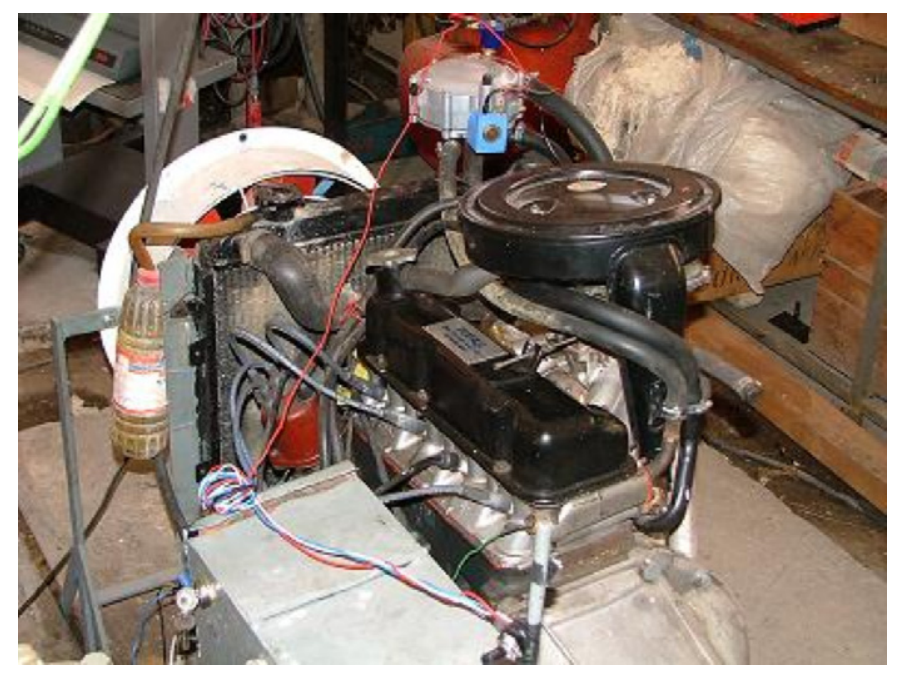

Fig. 2. Overview of the test engine.

The test engine was loaded with the help of eddy currenttype dynamometer. The maximum allowable speed of the dynamometer was defined as $4000 \mathrm{rpm}$. Since the speeds below $2600 \mathrm{rpm}$ caused serious backfire, the engine was run between 2600 and $3800 \mathrm{rpm}$. The engine test for each parameter was repeated three times and arithmetical average value was considered. Load applied to the engine was varied by using the knobs that change the current in the stator of eddy current dynamometer. A three-way switch was installed on the dashboard assembly that allows immediate switching from one fuel to the other. Therefore switching between fuels was possible without stopping the engine. In order to avoid temperature and pressure variations as far as possible, experiments with gasoline were immediately followed by hydrogen experiments with the engine already warmed up to operating temperature.

The brake torque, $T$, applied to the cradled housing was calculated by the moment arm connected to the balance weights [15]:

$T=F b$,

where $T$ brake torque in $\mathrm{Nm}, F$ applied load in $N$, and $b$ is a distance from the center of rotor in $\mathrm{m}$.

The brake power, $P_{\mathrm{b}}$, delivered by the engine and absorbed by the dynamometer is the product of torque and angular speed [15].

$P_{\mathrm{b}}=2 \pi \omega \mathrm{T} \times 10^{-3}$,

where $P_{\mathrm{b}}$ brake power in $\mathrm{kW}, \omega$ angular speed in rps, and $T$ brake torque in $\mathrm{Nm}$.

Another engine performance parameter is the mean effective pressure (MEP). Since the power used in the calculation is the brake power, so this pressure term is called the brake mean effective pressure (BMEP) [15].

$\mathrm{BMEP}=\frac{P_{\mathrm{b}} n_{\mathrm{r}} \times 10^{3}}{V_{\mathrm{d}} \omega}$,

where $P_{\mathrm{b}}$ brake power in $\mathrm{kW}, n_{\mathrm{r}}$ the number of crank revolutions for one complete cycle which is 2 for a four-stroke engine, $V_{\mathrm{d}}$ the total volume of the engine cylinders in $\mathrm{dm}^{3}$, and $\omega$ angular speed in rps.

The ratio of the work produced to the amount of heat energy released in the combustion process is called brake thermal efficiency $\left(\eta_{\mathrm{BT}}\right)[15]$.

$\eta_{\mathrm{BT}}=\frac{P_{\mathrm{b}}}{\dot{m}_{\mathrm{f}} Q_{\mathrm{LHV}}}$,

where $P_{\mathrm{b}}$ brake power in $\mathrm{kW}, \dot{m}_{\mathrm{f}}$ mass of supplied fuel in $\mathrm{kg} / \mathrm{s}$, and $Q_{\mathrm{LHV}}$ lower heating value of fuel in $\mathrm{kJ} / \mathrm{kg}$.

The first law analysis fails to determine the best evaluation of an engine operation. In order to prevent this situation, the second law analysis must be applied to find out inefficiencies associated with the processes, as well. The analysis consists of first and second laws of thermodynamics is called the exergy analysis and evaluates the thermodynamic performance of a system which is an SI engine for the present case. The exergy content shows the system potential to do useful work. In other words, exergy of a system in any given state can be defined as maximum useful work produced while it reaches mechanical, thermal and chemical equilibrium with its surroundings. The state chosen as reference dead state is very important for exergy analysis. Unless specified otherwise, the reference dead states are assumed to be $101.325 \mathrm{kPa}$ and $298.15 \mathrm{~K}$ for the mechanical and thermal equilibrium, respectively [16]. Molar composition of surroundings are $20.35 \% \mathrm{O}_{2}, 75.67 \% \mathrm{~N}_{2}, 0.03 \% \mathrm{CO}_{2}, 3.03 \%$ $\mathrm{H}_{2} \mathrm{O}$, and $0.92 \%$ other substances for chemical equilibrium. But chemical exergy cannot be realized as work in engine operations [17].

For an internal combustion engine, the following equation gives the total exergy rate [16]:

$$
\begin{aligned}
\dot{X}= & \sum\left(1-\frac{T_{0}}{T_{\mathrm{k}}}\right) \dot{Q}_{\mathrm{k}}-\left(\dot{W}-P_{0} \frac{\mathrm{d} V_{\text {system }}}{\mathrm{d} t}\right) \\
& +\sum \dot{m}_{\text {in }} \psi_{\text {in }}-\dot{m}_{\text {out }} \psi_{\text {out }}-\dot{I} .
\end{aligned}
$$

The first term on right-hand side above is exergy term associated with heat transfer at the boundary of the system, $\mathrm{k}$. The second term is exergy term associated with mechanical work transfer. The third and fourth terms are exergy terms associated with inlet and outlet masses, respectively. The last term is irreversibility rate of production. Main irreversibility sources are 
combustion, viscous dissipation, turbulence, throttling, mixing, and friction for an internal combustion engine. The first-law efficiency namely brake thermal efficiency reflects only energy losses and does not take irreversibilities into account. Therefore, second-law efficiency, $\varepsilon$, should be considered in order to give the best insight into the present engine operation.

$\varepsilon=\frac{P_{\mathrm{b}}}{P_{\mathrm{b}}+I}$

where $\mathrm{P}_{\mathrm{b}}$ brake power in $\mathrm{kW}, I$ irreversibility, especially due to combustion and heat transfer, in $\mathrm{kW}$. It should be noted that about $90 \%$ of irreversibility comes from combustion contribution [17].

\section{Results and discussion}

For detailed analysis, as many as possible operating point data have been recorded during the experiments [18]. The variation of brake torque versus engine speed is shown in Fig. 3. At a speed of about $3100 \mathrm{rpm}$ hydrogen operated engine reaches the torque values for gasoline operated engine and exceeds at greater speeds. Since hydrogen has fast burning characteristics, it is obvious to expect relatively better results at high speed operation condition.

Fig. 4 shows the brake power for both fuels. Due to its low specific energy content in terms of volume, hydrogen fuelled engine has less power output than gasoline fuelled one for the same engine size, especially at low speeds. But hydrogen fuelled engine starts to compete well after $3100 \mathrm{rpm}$ speed value. It is obvious that speed reduction increases mechanical losses. This disadvantage can be solved by supercharging. Supercharging also helps to cool off the cylinders.

Hydrogen fuel has higher brake thermal efficiency and even can operate at lower engine loads with better efficiency. It can be noticed that brake thermal efficiency is improved to about $31 \%$ with hydrogen fuelled engine compared to gasoline fuelled engine. Comparison of brake thermal efficiency of the fuels is shown in Fig. 5.

Gasoline combustion converts hydrocarbon molecules to light gaseous fragments, whereas hydrogen combustion converts two diatomic molecules to triatomic molecule [17].

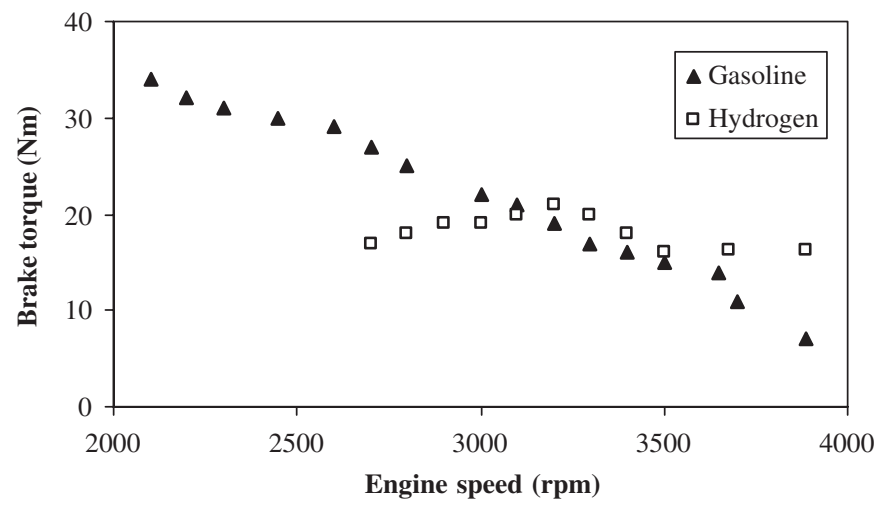

Fig. 3. Variation of brake torque versus engine speed.

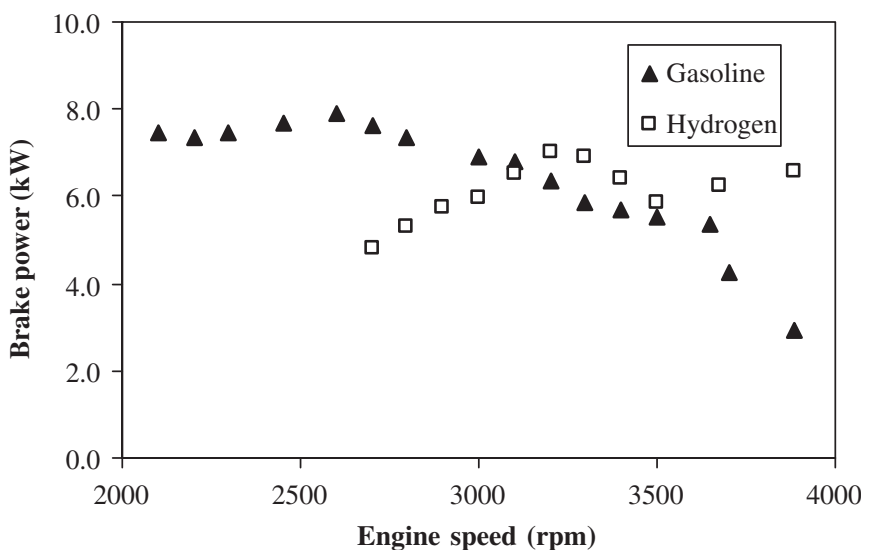

Fig. 4. Variation of brake power versus engine speed.

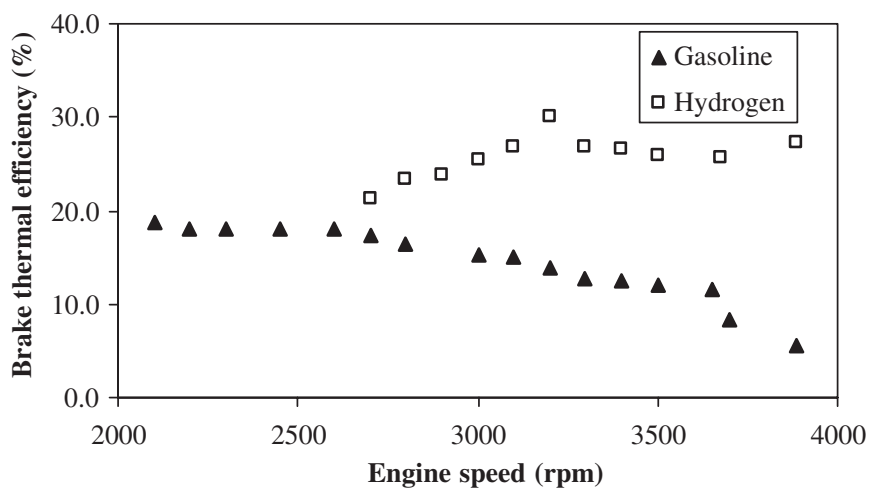

Fig. 5. Variation of brake thermal efficiency versus engine speed.

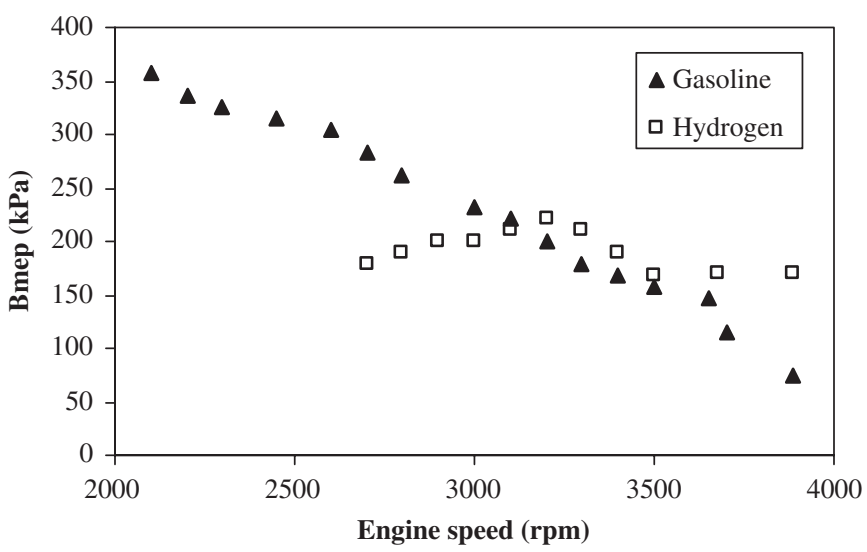

Fig. 6. Variation of brake mean effective pressure versus engine speed.

Therefore, hydrocarbon combustion increases entropy, hence irreversibility. Since $90 \%$ of irreversibility comes from combustion process, second-law efficiency increases in favor of hydrogen.

Another performance parameter, brake mean effective pressure, is shown in Fig. 6. Hydrogen operation shows a slight improvement at speeds above $3100 \mathrm{rpm}$.

Hydrogen combustion produces lower exhaust gas temperature due to high compression ratio. As soon as the hydrogen 


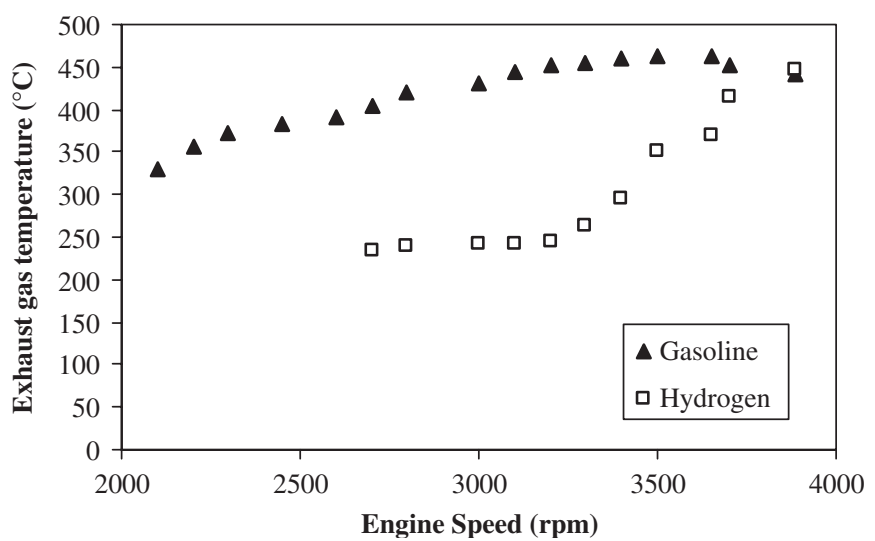

Fig. 7. Variation of exhaust gas temperature versus engine speed.

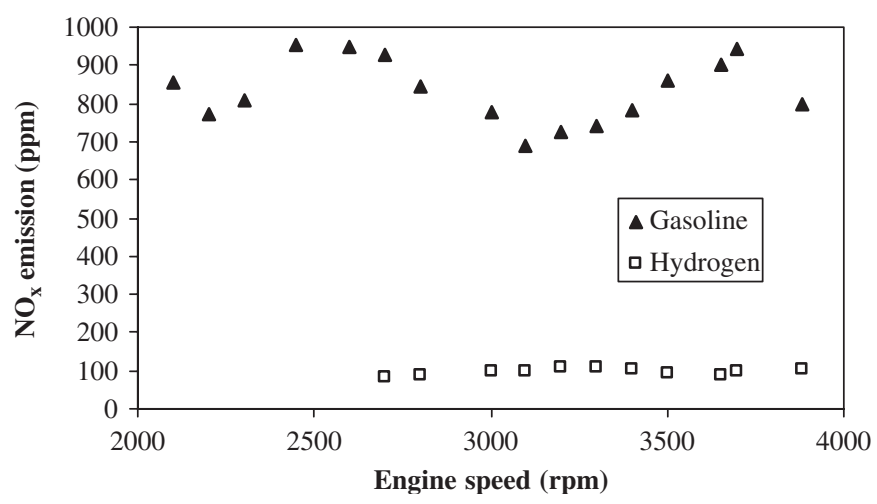

Fig. 8. Variation of $\mathrm{NO}_{x}$ emission versus engine speed.

engine gets into the high speed range, the exhaust temperature starts to increase significantly (Fig. 7) but remains under gasoline operated values. This is due to the cooling effect of sprayed water that is used for hydrogen operation, as well.

Fig. 8 illustrates $\mathrm{NO}_{x}$ levels of both engines. Significant decrease in $\mathrm{NO}_{x}$ emission is observed with hydrogen operation. Almost a 10-fold decrease can be noted, easily. The cooling effect of the water sprayed plays important role in this reduction. Also operating the engine with a lean mixture is kept $\mathrm{NO}_{x}$ levels low.

Fig. 9 shows $\mathrm{CO}$ emission versus engine speed for both engines. Although excess air for complete combustion is present in the cylinder, the engine is not capable of burning the total fuel. It was expected that hydrogen fuelled engine must have zero $\mathrm{CO}$ emission. As it is seen in Fig. 9, some amount of $\mathrm{CO}$ is still present. This is due to the burning of lubricating oil film inside the engine cylinder. As engine speed increases, $\mathrm{CO}$ emission tends to diminish.

A similar presentation of results for $\mathrm{CO}_{2}$ emission is seen in Fig. 10. Very low $\mathrm{CO}_{2}$ emission values for hydrogen fuelled engine are again due to combustion of the lubricating oil film.

The temperature caused by combustion is very high inside the cylinder. As the piston expends the heat evaporates some amount of oil. In addition to this evaporated oil, incompletely burned oil also contributes to $\mathrm{HC}$ emission shown in Fig. 11.

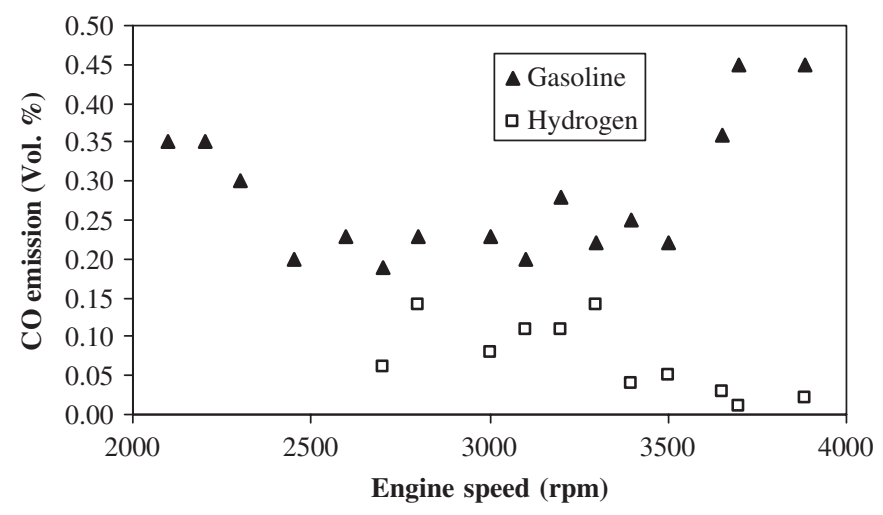

Fig. 9. Variation of $\mathrm{CO}$ emission versus engine speed.

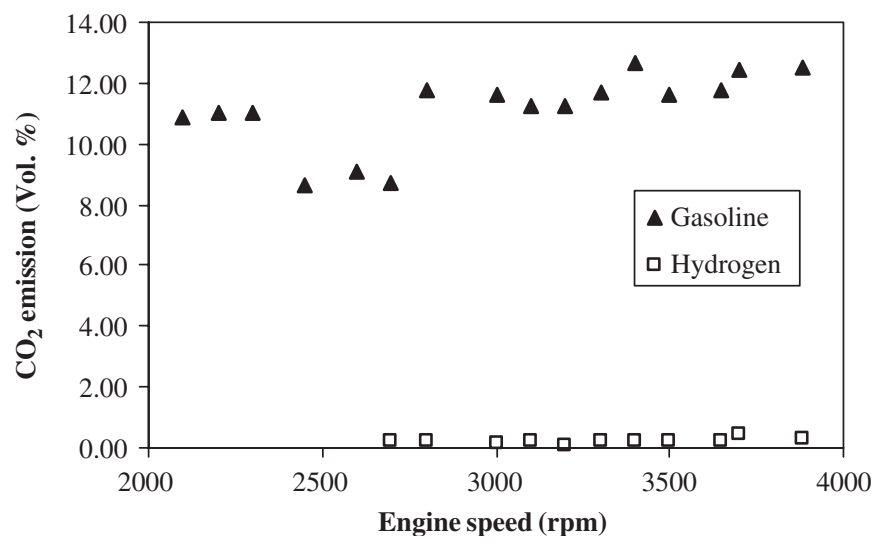

Fig. 10. Variation of $\mathrm{CO}_{2}$ emission versus engine speed.

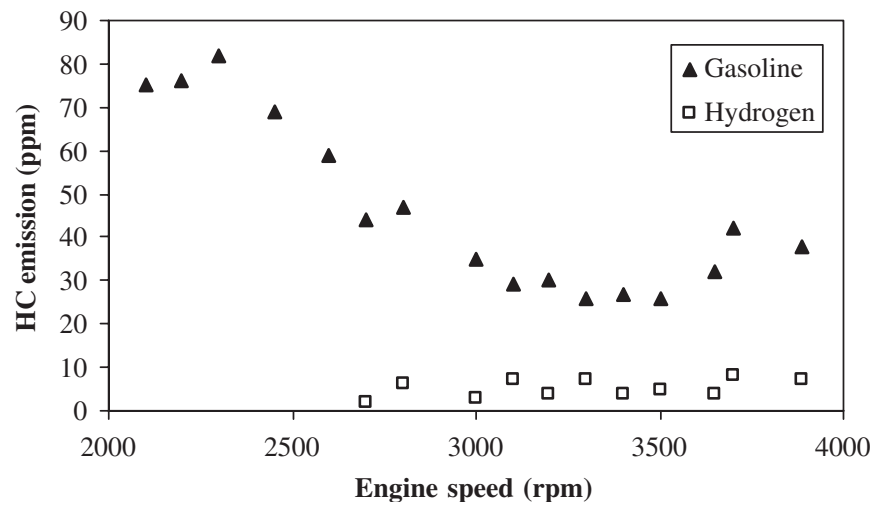

Fig. 11. Variation of $\mathrm{HC}$ emission versus engine speed.

At low engine speed, the gasoline fuelled engine was choked and more unburnt $\mathrm{HC}$ was present in the exhaust gases.

In hydrogen operating case, air-fuel mixture was leaned to cool down the cylinder and operate the engine without backfire problem. Since the engine was kept on lean side during the hydrogen operation, $\mathrm{O}_{2}$ emission level is much higher than gasoline fuelled engine (Fig. 12). 


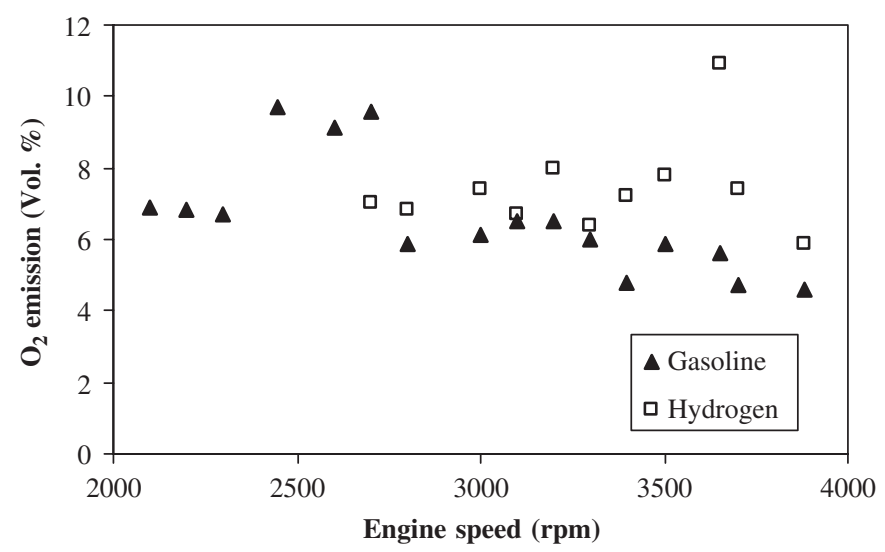

Fig. 12. Variation of $\mathrm{O}_{2}$ emission versus engine speed.

\section{Conclusions}

A conventional four-cylinder SI engine has been adopted to operate on gaseous hydrogen. Previous tests have been performed with the mixer installed on top of the carburetor body. Since serious backfire is observed with this type of installation, another mixer has been installed between the carburetor body and inlet manifold. Backfire is prevented by this configuration at engine speed above $2600 \mathrm{rpm}$. Specific features of the use of hydrogen as an engine fuel have been analyzed. The test results have been demonstrated that power loss occurs at low speed hydrogen operation whereas high speed characteristics compete well with gasoline operation. But, fast burning characteristics of hydrogen permit high speed engine operation. This allows increase in power output and efficiencies, relatively. $\mathrm{NO}_{x}$ emission of hydrogen fuelled engine is about 10 times lower than gasoline fuelled engine. The slight traces of $\mathrm{CO}$ and $\mathrm{HC}$ emissions presented at hydrogen fuelled engine are due to the evaporating and burning of lubricating oil film on the cylinder walls. Short time of combustion produces lower exhaust gas temperature for hydrogen. The first- and second-law efficiencies have improved with hydrogen fuelled engine compared to gasoline engine. It has been proved that hydrogen is a very good candidate as an engine fuel. Appropriate changes in the combustion chamber together with better cooling mechanism would increase the possibility of using hydrogen across a wider operating range. The future advances on hydrogen usage in SI engine depend on whether hydrogen can be obtained abundantly and economically as a fuel.

\section{Acknowledgments}

The authors wish to express their sincere thanks to Professor N. Sefa Kuralay who is in charge of the Dokuz Eylul University's Engine Laboratory, Dr. Atilay Yesil and laboratory technician Mr. Pehril Yavuzyugruk for their help during the engine tests.

\section{References}

[1] Veziroglu TN, Gurkan I, Padki MM. Remediation of greenhouse problem through replacement of fossil fuels by hydrogen. Int J Hydrogen Energy 1989;14(4):257-66.

[2] Veziroglu TN, Barbir FH. Hydrogen, the wonder fuel. Int J Hydrogen Energy 1992;17(6):391-404

[3] Das LM, Gulati R, Gupta PK. A comparative evaluation of the performance characteristics of a spark ignition engine using hydrogen and compressed natural gas as alternative fuels. Int J Hydrogen Energy 2000;25(8):783-93.

[4] Al-Baghdadi MARS, Al-Janabi HAKS. A prediction study of a spark ignition supercharged hydrogen energy. Energy Conver Manage 2003;44(20):3143-50.

[5] Das LM. Hydrogen engine: research and development (R\&D)programmes in Indian Institute of Technology (IIT). Delhi Int J Hydrogen Energy 2002;27(9):953-65.

[6] Karim GA. Hydrogen as a spark ignition engine fuel. Int J Hydrogen Energy 2003;28(5):569-77.

[7] Li H, Karim GA. Knock in spark ignition hydrogen engine. Int J Hydrogen Energy 2004;29(8):859-65.

[8] Homan HS. An experimental study of reciprocating internal combustion engines operated on hydrogen. PhD thesis, Cornell University, 1978.

[9] Al-Baghdadi MARS. Effect of compression ratio, equivalence ratio and engine speed on the performance and emission characteristics of a spark ignition engine using hydrogen as a fuel. Renewable Energy 2004;29(15):2245-60.

[10] Li H, Karim GA. Exhaust emissions from an SI engine operating on gaseous fuel mixtures containing hydrogen. Int $\mathrm{J}$ Hydrogen Energy 2005;30(13-14):1491-9.

[11] Al-Baghdadi MARS. Performance study of a four-stroke spark ignition engine working with both of hydrogen and ethyl alcohol as supplementary fuel. Int J Hydrogen Energy 2000;25(10):1005-9.

[12] 〈http://www.greencarcongress.com $\rangle$.

[13] 〈http://www.hotlib.com $\rangle$.

[14] Peschka W. Hydrogen: the future cryofuel in internal combustion engines. Int J Hydrogen Energy 1998;23(1):27-43.

[15] Heywood JB. Internal combustion engine fundamentals. New York: McGraw-Hill; 1989.

[16] Cengel YA, Boles MA. Thermodynamics: an engineering approach. New York: McGraw-Hill; 1998.

[17] Rakopoulos CD, Giakoumis EG. Second-law analysis applied to internal combustion engines operation. Prog Energy Combust Sci 2006;32(1): 2-47.

[18] Kahraman E. Analysis of a hydrogen fuelled internal combustion engine. MSc thesis, Izmir Institute of Technology; 2005. 